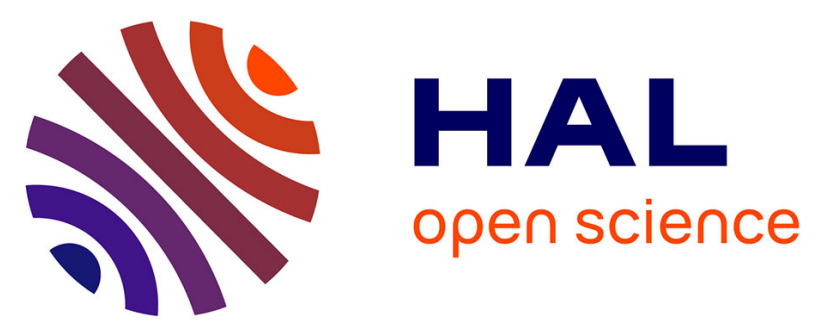

\title{
Methodology for the in situ characterisation of soil vapor contaminants and their impact on the indoor air quality of buildings
}

Bernard Collignan, Thierno M.O. Diallo, Sylvie Traverse, Juliette Chastanet, Marc O. Abadie, Emilie Powaga, Corinne Hulot, Zaid Romani, Francis Allard, Marie Grasset

\section{To cite this version:}

Bernard Collignan, Thierno M.O. Diallo, Sylvie Traverse, Juliette Chastanet, Marc O. Abadie, et al.. Methodology for the in situ characterisation of soil vapor contaminants and their impact on the indoor air quality of buildings. Building and Environment, 2020, 177, pp.106900. 10.1016/j.buildenv.2020.106900 . hal-02556438

\section{HAL Id: hal-02556438 https://hal.science/hal-02556438}

Submitted on 2 Jul 2021

HAL is a multi-disciplinary open access archive for the deposit and dissemination of scientific research documents, whether they are published or not. The documents may come from teaching and research institutions in France or abroad, or from public or private research centers.
L'archive ouverte pluridisciplinaire HAL, est destinée au dépôt et à la diffusion de documents scientifiques de niveau recherche, publiés ou non, émanant des établissements d'enseignement et de recherche français ou étrangers, des laboratoires publics ou privés. 


\title{
Methodology for the in situ characterisation of soil vapor contaminants and their impact on the indoor air quality of buildings
}

Bernard Collignan ${ }^{1}$, Thierno M.O. Diallo ${ }^{1}$, Sylvie Traverse ${ }^{2}$, Juliette Chastanet $^{2}$, Marc Abadie $^{3}$, Emilie Powaga ${ }^{1}$, Corinne Hulot ${ }^{4}$, Zaïd Romani ${ }^{3}$, Francis Allard ${ }^{3}$, Marie Grasset $^{5}$

${ }^{1}$ CSTB, Health and Comfort Department. 24 Rue Joseph Fourier, 38000 Grenoble, France.

2BURGEAP, 19 Rue de la Villette, 69003 Lyon, France.

${ }^{3}$ University of La Rochelle, 23 Avenue Albert Einstein, 17000 La Rochelle, France.

${ }^{4}$ INERIS, 60550 Verneuil en Halatte, France.

${ }^{5}$ Grand Lyon, Métropole de Lyon 20, rue du Lac, 69505 Lyon, France.

Corresponding author: bernard.collignan@cstb.fr Tel.: +33 476762525

\begin{abstract}
This study presents a fast and nonintrusive in situ methodology to characterise the Volatile Organic Compounds (VOCs) fluxes of contaminated sites and to quantify their intrusion into future buildings built on these sites. It could be used to conduct exhaustive ground pre-characterisation and indoor air assessments for future on-site buildings. The methodology involved the use of a specific apparatus called the "experimental box", representing convective and diffusive transfers of soil gas pollutants into buildings, to quantify an equivalent homogeneous concentration of the contaminant in the soil gas. Furthermore, this equivalent homogeneous concentration was used to quantify the indoor air pollutant concentration in a future building using an analytical transfer model associated with a numerical ventilation model. This methodology was applied on an experimental site. A critical analysis highlights its interest as a powerful complementary tool to constitute complementary support for decision-making methods and for human health risk assessment.
\end{abstract}

Keywords: soil vapor intrusion; experimental characterisation; building ventilation; modelling; indoor air quality; health risk assessment

\section{Introduction}

The transfer of vapor contaminants from subsurface soil or groundwater into buildings, referred to "vapor Intrusion", can cause serious human health risks [1,2]. Currently, construction on contaminated sites represents economic and social issues because of the real state pressure that accentuates the need to build on former industrial contaminated sites that are situated generally in suburban areas. Therefore, before any building construction, there is a need to characterise residual contaminated sites and to assess the human health risks associated with the intrusion of vapor contaminants into buildings that would be built on these sites.

However, available numerical and experimental methods to conduct such characterisations are sometimes complicated to apply, and the results could be 
difficult to interpret due to complex phenomena that could be involved, inducing the possible spatial and temporal variability of pollutant concentration in the ground due, for example, to the presence of a non-uniform source of pollutant $[3,4]$.

Different methods have been developed to characterise soil contaminant vapors: soil gas collection, by driving a tube or rod, often called a "probe", into the soil or by burying a small-diameter tube in the soil, passive soil gas collection (absorbent material designed to collect volatile chemicals). More particularly in recent years, flux chambers have been widely used for the assessment of soil gas pollutant emissions from the subsurface to the atmosphere $[4,5,6,7,8,9,10,11,12,13]$.

However, some issues have been raised concerning the use of such tools to evaluate vapor intrusion into buildings because only diffusive transfer is measured, and the method cannot consider the effect of building foundations. The mass flux into buildings is governed by diffusive and convective transfers induced by the slight indoor depression due to various factors: the stack effect, the effect of wind on the building envelope, or the impact of ventilation systems [14]. Additionally, building foundation types influence the movement of vapors [15]. Thus, with flux chambers, the measured mass fluxes can be biased because they cannot reproduce the internal flow coming into the building. Some studies noticed that when using a "flux chamber" on a ground surface, one method to consider the attenuation due to the presence of building foundations is to multiply the measured fluxes by a factor of 0.01 $[16,17,18,19]$. This approach has been used as a method to determine indoor concentrations from "flux chamber" measurements, but it has not been validated and scientifically approved as a method for assessing the risk associated with vapor intrusion into buildings. To consider the depression induced in a building, Schmidt et al. [17] developed and tested a procedure that permits the creation in a "flux chamber" of inside/outside pressure differences comparable to those observed in buildings. Their goal was to create a "mini-building" in which flux measurements could be made. However, the induced inside/outside pressure difference in their "flux chamber" to represent real building behaviour has not been validated. Recently, Heggie and Stavropoulos [20,21] developed a method to quantify the diffusive mass flux of VOCs from natural grounds, floors and pavements by using "passive diffusive flux chambers". Their method uses "a high uptake rate passive absorptive sampling tube" placed within the chamber to measure the contaminant mass flux. They highlighted that their method considers only the diffusion phenomenon and does not consider possible convection through building foundations. They mentioned that the comparison between their passive flux chamber and the traditional flux chamber [14] showed that the measured mass flux using the passive flux chamber is two times greater than the measured mass flux using the traditional flux chamber. To quantify the indoor concentration, the measured contaminant mass fluxes were used in a simple dilution model. However, the need for field validation and the limitation associated with the quantification of infiltration rates compromises the "flux chamber" to directly evaluate the transfer of soil pollutants into indoor environments. Different guidance documents on vapor transfer in indoor environments $[4,22,23]$ recommend quantifying pollutant sources in soil through gas and groundwater sampling and then using these data measurements as a means of assessing indoor air exposure. This EPA guidance document does not provide information on the use of "flux chambers" to estimate the impact of gaseous pollutants from the soil on indoor air quality. In contrast, the document indicates that "flux chamber" measurements can be used as 
an additional source of data to evaluate the transfer of soil gas pollutants from the soil to sites where no building exists yet. As a result, the EPA has not recommended flux chambers as a tool for assessing the transfer of vapors into indoor environments. Otherwise, the EPA recommendations are in line with the proposition made in this study to first characterise the equivalent homogeneous concentration of pollution in the soil and then use this limit condition to assess the impact of soil gas pollution on the indoor environment through a vapor intrusion model.

In this paper, a novel methodology to conduct an in situ characterisation of vapor (VOCs) fluxes from contaminated sites and their impact on Indoor Air Quality (IAQ) is developed. This methodology consists of three main steps: i- the experimental characterisation of vapor contaminant flux coming from the soil by using a novel "experimental box"; ii- the evaluation of the "equivalent homogeneous concentration" of pollution in the soil associated with a specific depth; and iii- the estimation of the resultant indoor concentration of the contaminant in a building taking into account its own characteristics. This paper presents the principles of this methodology. Furthermore, the methodology was applied in a contaminated site to assess its limits and potentialities.

\section{Material and methods}

The proposed methodology consists, on the one hand, of the in situ characterisation of sites contaminated by vapors and, on the other hand, of evaluating the impact on their intrusion into future buildings that would be built on these sites. The methodology consists of three main steps:

- The first step consists of the quantification of the soil contaminant mass flux by using a novel "experimental box" that aims to reproduce the behaviour of a real building. The principles of this quantification are based on previous works conducted to assess radon flux from the ground coming into a building [24,25].

- The second step consists of the characterisation of an equivalent homogeneous concentration of the contamination associated with a given depth, using the experimental results obtained with the "experimental box". This equivalent homogeneous concentration is evaluated by using an inverse method [26]. The knowledge of the pollutant concentration inside the "experimental box", the extracted airflow and the level of depression inside the "experimental box" enable us to estimate the equivalent homogeneous concentration for a given depth in the soil using an analytical model of soil pollutant transfer [15].

- The third step consists of the quantification of the indoor concentration of the contaminant by using a multizone ventilation model associated with the analytical model of pollutant transfer. The equivalent homogeneous concentration determined in the previous step and associated with a given depth is used as the limit condition to quantify the mass flux of the pollutant entering through the substructure of the building.

The following subsections present the details of each step of the methodology.

\subsection{Development of the innovative "experimental box" and estimation of the contaminant mass flux}


The goal of the novel "experimental box" design is to provide a flux chamber that is representative of the phenomena involved in a real building in terms of indoor depression and pollutant transfers (convection and diffusion) at the soil/building interface (building foundations).

The "experimental box" consists of an airtight circular box made with steel with a diameter of $1.2 \mathrm{~m}$, height of $0.5 \mathrm{~m}$ and anchoring in the ground of approximately $0.1 \mathrm{~m}$ (Fig. 1). A material with calibrated air permeability has been placed at the interface between the ground surface and the chamber. The calibrated air permeability consists of 16 openings of $4 \mathrm{~mm}$ diameter equally distributed at the surface of the interface. It has been dimensioned with preliminary laboratory tests to correspond to the air permeability of a building slab between $1.210^{-12} \mathrm{~m}^{2}$ and $710^{-12}$ $\mathrm{m}^{2}$, depending on the number of openings considered. Thus, it enables us to consider the whole air permeability of a slab, including cracks. In addition, mechanical air extraction was included and controlled to generate a representative depression of a real building inside the box. Furthermore, the chamber was equipped with air inlets that permit, if necessary, control of the extracted airflow and the resulting depression inside the chamber. In addition to airflow and pressure measurements, the concentration of pollutant is measured continuously at the exhaust to be representative of the averaged concentration into the box under steady-state conditions.

During box operation, when steady-state conditions have been reached, it is possible to estimate the vapor contaminant mass flux $J_{p}\left(\mu g_{.} \mathrm{s}^{-1}\right)$ entering the chamber by using the following expression:

$J_{p}=C_{c} \cdot Q_{c}$

where $\mathrm{C}_{c}\left(\mu \mathrm{g} \cdot \mathrm{m}^{-3}\right)$ is the average contaminant concentration at the extraction point and $Q_{c}\left(\mathrm{~m}^{3} \cdot \mathrm{s}^{-1}\right)$ is the extracted airflow rate.

\subsection{Evaluation of the "equivalent homogeneous concentration" of the pollutant}

This section presents the vapor intrusion model specially developed for the novel "experimental box" and based on previous works [15,26]. This permits the estimation of the equivalent homogeneous concentration of the pollutant at a given depth.

\subsubsection{Presentation of the transfer model}

By using the analogy between the heat transfer (Fourier's law) and airflow behaviour (Darcy's law) in porous media, Diallo et al. [15] developed analytical airflow models quantifying the airflow from soil to different building substructures. Furthermore, Diallo et al. [27] developed semi-empirical models (SEM) to quantify the mass flux of soil gas pollutants entering different building substructures (supported slab, floating slab and crawl space). These models have been adapted to the "experimental box" by considering the particularity of the box geometry as well as the particularity associated with the interface material. The resulting models have been used to exploit the experimental data obtained with the use of the "experimental box". 


\section{Airflow from the ground into the experimental box:}

$Q_{\text {air }}=\frac{2 \mathrm{k}_{\text {soil }} \Delta \mathrm{P}}{\mu}\left[\frac{\mathrm{L}_{\text {slab }}}{2}-\beta \ln \left(\frac{1+\alpha\left(\mathrm{L}_{\text {slab }}+\mathrm{E}_{\mathrm{j}}\right)}{1+\alpha \mathrm{E}_{\mathrm{j}}}\right)\right]$

with

$$
\beta=\frac{1}{2 \alpha}
$$

and

$$
\alpha=\frac{\pi \mathrm{k}_{\text {slab }} \mathrm{k}_{\text {grav }}}{2\left(2 \mathrm{k}_{\text {slab }} \mathrm{k}_{\text {grav }} \mathrm{E}_{\mathrm{e}}+\mathrm{k}_{\text {slab }} \mathrm{k}_{\text {soil }} \mathrm{E}_{\text {grav }}+\mathrm{k}_{\text {slab }} \mathrm{k}_{\text {grav }} \mathrm{E}_{\text {grav }}+\mathrm{k}_{\text {soil }} \mathrm{k}_{\text {grav }} \mathrm{E}_{\text {slab }}\right.}
$$

where Qair $\left(\mathrm{m}^{3} \cdot \mathrm{s}^{-1} \cdot \mathrm{m}^{-1}\right)$ is the airflow rate per linear metre of connection, $\mathrm{k}_{\text {soil }}\left(\mathrm{m}^{2}\right)$ is the air permeability of the soil, $\mathrm{k}_{\mathrm{slab}}\left(\mathrm{m}^{2}\right)$ is the air permeability of the interface, kgrav $\left(\mathrm{m}^{2}\right)$ is the air permeability of the gravel layer or the air layer under the interface $\left(\mathrm{m}^{2}\right)$, $E_{e}(m)$ is the depth of the chamber wall in the ground, $E_{j}(m)$ is the thickness of the chamber wall in the ground, $E_{\text {grav }}(\mathrm{m})$ is the depth of the gravel or the air layer under the interface, Eslab $(m)$ is the thickness of the interface, Lslab $(m)$ is the characteristic length of the interface, $\Delta \mathrm{P}(\mathrm{Pa})$ is the pressure difference between the inside of the box and the outside and $\mu$ (Pa.s) is the dynamic viscosity of the air. The mass flux of the vapor contaminant in the chamber is given by eq. (1).

\section{Pollutant concentration in the chamber:}

$C_{p}=\mathrm{C}_{\mathrm{S}}\left(\mathrm{ABB}^{1 / \mathrm{Pe}} \mathrm{Pe}^{\mathrm{C}}\right)\left(0.479+0.481 \frac{\mathrm{H}_{0}}{\mathrm{H}}\right)$

with:

$$
\mathrm{Pe}=\frac{\left(\frac{\mathrm{e}_{\text {slab }}}{D_{\text {slab }}}+\frac{\mathrm{H}_{\text {soil }}}{D_{\text {soil }}}\right)}{1 /\left(\frac{Q_{\text {air }}}{A_{i}}\right)}=\left(\frac{Q_{\text {air }}}{A_{i}}\right)\left(\frac{e_{\text {slab }}}{D_{\text {slab }}}+\frac{H_{\text {soil }}}{D_{\text {soil }}}\right)
$$

where $C_{p}\left(\mu \mathrm{g} \cdot \mathrm{m}^{-3}\right)$ is the concentration inside the flux chamber; $C_{s}\left(\mu \mathrm{g} \cdot \mathrm{m}^{-3}\right)$ is the concentration at the source; $A=7.068 \times 10^{-4} ; B=3.37 \times 10^{-12} ; C=-0.251 ; A_{i}\left(m^{2}\right)$ is the surface of the interface; $D_{\text {slab }}\left(\mathrm{m}^{2} \cdot \mathrm{s}^{-1}\right)$ is the diffusion coefficient of the slab; eslab $(m)$ is the thickness of the slab; $\mathrm{H}_{\text {soil }}(\mathrm{m})$ is the depth of the source; $\mathrm{H}_{0}(\mathrm{~m})$ is the reference depth; $D_{\text {soil }}\left(\mathrm{m}^{2} . \mathrm{s}^{-1}\right)$ is the diffusion coefficient of the soil.

In eq. (3), empirical coefficients are determined based on a computational fluid dynamic (CFD) sensitivity study, which represents phenomena for a given range of variation in relevant parameters, using the same method presented in [15].

\subsubsection{Estimation of the "equivalent homogeneous concentration"}

The knowledge of the contaminant mass flux coming into the box at steadystate conditions permits the determination of the "equivalent homogeneous 
concentration" of the contaminant pollution for a given depth of $\mathrm{H}_{\text {soil }}$ by inverse use of the previous formula (eq. (3)) as follows:

$$
\mathrm{C}_{\mathrm{S}}=\frac{\mathrm{C}_{\mathrm{p}}}{\left(\mathrm{A} \mathrm{B}^{1 / \mathrm{Pe}_{\mathrm{Pe}} \mathrm{C}}\right)\left(0,479+0,481 \frac{\mathrm{H}_{0}}{\mathrm{H}_{\text {soil }}}\right)}
$$

This equivalent homogeneous concentration at a given depth $\mathrm{H}_{\text {soil }}$ corresponds to virtual conditions in the contaminated site that would generate the same vapor mass flux in the "experimental box" as the real contamination. It should be noted that the value of the contaminant mass flux coming into the box cannot be used directly to assess incoming flux in a virtual building because the geometries are different. However, the value enables the determination of the equivalent homogeneous concentration at a given depth. The interest is then to use these latter values numerically to estimate the indoor concentration in a building as presented in $\S 2.3$.

\subsubsection{Estimation of the "equivalent soil permeability"}

Otherwise, the use of eq. (2), which quantifies the airflow from the soil entering the chamber, combined with the experimental knowledge of the airflow inside the chamber as well as the inside depression, permits us to calculate an "equivalent air permeability of the soil" impacted by convective flux induced by the running of the experimental box".

\subsection{Estimation of the indoor concentration in a building}

Once the equivalent homogeneous concentration has been determined at a given depth, this value is used to quantify the mass flux of the pollutant entering a real building. Then, the resulting mass flux, obtained by using the vapor intrusion model, is used as the source term in the mass conservation equation of the ventilation model. This integration permits us to predict the evolution of the indoor concentration of the contaminant and then to quantify the human health risk associated with vapor intrusion into buildings.

\subsubsection{Building substructure influence}

The SEM developed by Diallo et al. [27] considers different building substructures (floating slab, supported slab and crawl space). Then, these models can be easily used to estimate the mass flux of the vapor contaminant entering most encountered building substructures, depending on the depressurisation level of the building.

\subsubsection{Integration of the contaminant mass flux in a multizone ventilation model}

The model used in this study (MATHIS-QAI) is an unsteady ventilation model for buildings developed by CSTB [28]. This model permits computation of the indoor air concentration of the pollutant for each time step. The model is based on a nodal resolution method, which means that the different zones of the building are represented by a single node for the different state variables (temperature, pressure). 
At each time step, the resolution principle is to realise the mass balance between the inside and the outside of the building as well as in each zone:

$\sum \dot{m}_{i}=0$

where $\dot{m}_{i}\left(\mathrm{~kg} \cdot \mathrm{s}^{-1}\right)$ is the mass flow incoming or outgoing through a component "i" of the considered zone.

Power laws are conventionally used to express the airflow as a function of the pressure difference across a building component. These components may be ventilation devices (air inlets, extraction or insufflation vents, mechanical or natural) and elements of the envelope permeability (leaks). For the ventilation devices, the corresponding law is determined experimentally according to the device characteristics. For the envelop permeability, it could be characterized using a blower door test or using a default value. In addition, internal and external hydrostatic pressure fields depend on the ground atmospheric pressure, indoor and outdoor temperatures, and wind velocity and direction. Knowing for each time step the meteorological conditions and the indoor temperature and assuming the external ground pressure as the reference, eq. (5) can be written as depending only on the internal pressure at ground level for the considered zone [29]:

$f\left(P_{0}^{i n t}\right)=0$

Then, the program computes for each time step the incoming and outgoing airflows for each zone over the considered period, up to several years, as well as the level pressure difference between inside and outside the building, especially at the floor level. The integration of the SEM in the MATHIS-QAI ventilation code allows for each time step to compute the mass flux of the vapor contaminant entering the building and to calculate the resulting indoor concentration of pollutant in each room. Fig. 2 shows the integration of SEM models in the multizone ventilation model.

\section{Results}

This section demonstrates the above methodology for a contaminated site near Lyon in France.

\subsection{Presentation of the experimental site}

The site is located in an alluvial meander of a large river near the city of Lyon France. Historical activities generated pollution of the vadose zone soil and aquifer with petroleum hydrocarbons (mixture of gasoline and diesel) in the soil gas; essentially, aliphatic hydrocarbons are present at elevated concentrations. The soil in the vadose zone presents an alternation of silts and sands as classical alluvial soils. The encountered lithologies on the site are heterogeneous embankments up to $1.3 \mathrm{~m}$ deep, an alternation of gravelly sand and silts up to $9 \mathrm{~m}$ deep, silts and/or sands in the water table zone between 9 and $11 \mathrm{~m}$ deep and an underlying sandy aggregate. The level of groundwater on the site (fluctuation between 8 and $11 \mathrm{~m}$ depth) is dependent on the level of the nearby river. A supernatant organic phase at the top of the aquifer is measured on most of the implanted piezometers on the site except for 
part of the northern zone. Fig. 3 shows a view of the site plan and the position of the north zone selected for the study.

To support and validate the methodology, measurements were carried out in the considered zone of the site (Fig. 4). Pre-characterisation of the "northern" zone was performed by using a soil gas probe at a depth of $1 \mathrm{~m}$ with a photoionisation detector and a multi-gas analyser $\left(\mathrm{O}_{2} / \mathrm{CO}_{2}\right)$. Concentrations were measured by active sampling with activated carbon, extraction by CS2 and quantification by GC-MS. These diagnostics show the heterogeneity of the concentrations associated with a lateral source of hydrocarbons in the unsaturated soil in addition to the source present in the water table lowering zone. Then, the experimental area was instrumented with several soil gas probes (Fig. 5) to characterise the hydrocarbon soil gas concentration at depths of $0.5,1,3,5$ and $7 \mathrm{~m}$ during the experiments. A meteorological station was installed near the studied zone, enabling to collect different parameters: air temperature, relative humidity, wind speed and direction.

\subsection{Presentation of the "experimental box" and associated measurements}

As mentioned above, the box has been designed to reproduce the pressure conditions and airflows of a real building to be able to consider convective and diffusive pollutant transfers from the ground to a building. The box consists of 3 parts: a part of the box wall buried in the ground (skirt), a calibrated permeability interface and a lateral wall of the box and a cover. The air exchange and depression of the experimental chamber is possible due to the combination of a modular air inlet integrated into the cover and a variable-speed air extraction pump that can generate a depression from 1 to $50 \mathrm{~Pa}$ in the experimental chamber. The metrology of the box consists of devices that allow us to measure the extracted airflow, the depression inside the chamber and the inside temperature and humidity. Fig. 6 shows the different steps of the on-site installation of the flux chamber.

Fig. 7 shows the evolution of the contaminant concentration in the box and below the interface to reach steady-state conditions. The dynamic behaviour for the evolution of concentration is different between the two tests. This should be due to the different groundwater contents impacting the soil air permeability between the two tests (see Fig. 8).

The concentrations of VOC were measured by using a photoionisation detector for continuous monitoring and with active sampling on activated carbon allowing the quantification of different existing hydrocarbon fractions. The PID resolution is less than 1\% (1 ppm for concentration in the soil between 1000 and $9999 \mathrm{ppm}$ and $1 \mathrm{ppb}$ for concentration in the box between 0 and $9999 \mathrm{ppb})$. Therefore, the uncertainty is more due to the measurement method, as the device, responding to all VOCs and fractions different from those sought can thus modify the signal. The uncertainty associated with such interference has not been quantified. The instrument is calibrated with isobutylene at $10000 \mathrm{ppm}$ for the soil and $10 \mathrm{ppm}$ for indoor air). However, the values of concentrations of total hydrocarbon (in equivalent isobutylene) are not used for the quantification of the flux. Only the shape of the PID curve is used with the average concentrations measured with GC-MS during the experiment to estimate the steady-state hydrocarbon concentration. The uncertainty of these measurements was quantified at $35 \%$. Table 1 summarises the 
experimental conditions of the two tests that were exploited in this study, test $n^{\circ} 3$ and test $n^{\circ} 10$, carried out during July and November 2016, respectively. As previously explained, the steady-state conditions presented in this table are extrapolated using the exponential regression of temporal evolutions presented in Fig. 7. The total hydrocarbon concentrations were considered in this study (sum of the aliphatic fractions C5 to C10). The inside concentration of the contaminant $C_{p}$ in eq. (4) corresponds to the concentration at the exhaust of the box and refers to the averaged indoor concentration under steady-state conditions. It should be noted that the concentration designated "inside the box" was obtained with sampling located near the interface. During the experiment, it was shown that this concentration differs from the concentration at the exhaust of the box. This result reflects a nonhomogeneous concentration of pollutant in the box. Thus, this is the concentration at the exhaust of the box that is representative of the averaged concentration in steadystate conditions. For test 10, for which the concentration at the exhaust of the box could not be measured, an evaluation from the concentration inside the box was carried out by multiplying the latter by 0.54 (calculated coefficient from the results of another test). The knowledge of the pressure difference between inside and outside the experimental box permits the determination of the airflow Qair (eq. (2)). The air exchange rate in the box is calculated from the extracted flow during the test.

\subsection{Analytical determination of the equivalent soil characteristics}

From the above experimental results and as explained in $\S 2.2$, it is possible, using the inverse method, to deduce pairs of values ("equivalent homogeneous concentration", depth). These pairs were thus evaluated for different depths and the resulting soil gas concentrations. These values were compared to field measurements performed during the experiments.

Fig. 8 shows the measured and modelled concentration profiles under the box for depths ranging from 0.1 to $5 \mathrm{~m}$. The minimum and the maximum measurements presented in this figure correspond to the minimum and the maximum values obtained with the probes located around the box for different depths (fig. 5). As a result, and as previously said in $\S 3.1$, these measurements show the spatial heterogeneity of the concentrations. Those heterogeneities are more important near the surface and are presumably due to the likely lateral position of the pollutant source, associated with the probable variation in meteorological conditions as illustrated in Chastanet et al. (2018) [30]. For the calculations, it should be noted that the model correctly evaluates an equivalent homogenous concentration for the test $\mathrm{n}^{\circ} 3$, corresponding to the concentrations measured, except for the depth $5 \mathrm{~m}$. Differences observed for this depth could be explained by the fact that the presence of the source of pollutant is less important at those depths and such source profile heterogeneity can't be modeled using the analytical solution developed like previously mentioned, The objective of this modeling is not to represent the real concentration profile but to evaluate an equivalent homogeneous source of this pollution. For the test $n^{\circ} 10$, calculations overestimate the maximum values measured for all depths. However, for depths $1 \mathrm{~m}$ and $3 \mathrm{~m}$, the order of magnitude is quite acceptable in response to the principle of not underestimating the source of the pollutant. Another possible reason for this overestimation is the value of the diffusion coefficient of pollutant in soil, arbitrary chosen at $10^{-8} \mathrm{~m}^{2} / \mathrm{s}$ for the modeling, that is a

sensitive parameter of the model. Additionally, the real value of the diffusion 
coefficient is difficult to determine experimentally. This is a weakness of current models dealing with gaseous pollutant transfers from the ground.

The adaptation of the Diallo et al. models [27] allows, as already mentioned, the development of a model dedicated to the geometry of the box. It has been shown that the use of the airflow model from experimental data allows the determination of an equivalent air permeability of the soil under the box impacted by convection transfer in the ground. The above-developed diffuse-convective model has proven reliable in evaluating an "equivalent homogeneous concentration" representative of the emission of a contaminant in a real site. As with any model, it is important to emphasise the need for some input parameters, such as those obtained during the experimental phase: depression, air exchange rate and steady-state concentration, and some media properties: permeability of the soil and the diffusion coefficient of the pollutant.

In addition, it has been shown (§ 2.2.3) that the use of the airflow model (eq. (2)) from experimental data allows the determination of an "equivalent air permeability of the soil" under the box and in the convection zone. Fig. 9 shows a comparison between the calculated "equivalent air permeability" and the values measured at different depths and locations around the box during experiments. Measurements in the soil were conducted with a Gilair-branded pump (estimated onsite uncertainty - 5\%), and the differential pressure measurement using a GREISINGER-branded manometer (uncertainty $0.1 \%$ ). Thus, the developed methodology permits us to obtain a satisfactory order of magnitude of the soil permeability.

\subsection{Numerical calculation of the indoor concentration of the contaminant}

This section presents a case to estimate the evolution of the indoor contaminant concentration by using the ventilation model presented above associated with SEM. This estimation considers the main building envelope characteristics (typology of the foundations, air permeability of the building envelope) and ventilation systems. The prediction of the indoor contaminant concentration evolution will permit the assessment of the human health risk associated with soil contamination.

\subsubsection{Presentation of the case study}

For this case study, a two-level reference house described in Fig. 10 and Table 2 has been considered. From the experiments carried out and for illustrative purposes, the soil characteristics selected for these calculations are presented in Table 3. Based on the above input data, a sensitivity study on the variability of the following building parameters has been performed.

(i) Typology of the substructure: the two most-encountered building substructures in France have been considered, i.e., a floating slab (FS) with a peripheral crack of 1 $\mathrm{mm}$ thickness and a supported slab (SS).

(ii) Building envelope air permeability: The air permeability indicator of the building envelope $\mathrm{Q}_{4 \mathrm{~Pa}}$ corresponds to the leakage rate per building envelope external surface area under a negative relative pressure of $4 \mathrm{~Pa}$. It corresponds to the 
referential indicator used in French thermal regulation. The relationship between this indicator and the more classical one $\mathrm{q} 50\left(\mathrm{~m}^{3} / \mathrm{h}\right)$ which corresponds to the air leakage rate at $50 \mathrm{~Pa}$ defined in [31], is as followed: $Q_{4 P a}=(4 / 50)^{n} .950 / A_{E}$, with $A_{E}\left(m^{2}\right)$ corresponding to the area of the envelop of the building. The larger this indicator is, the more the building is permeable to air. For the calculations performed in this study, two values of this indicator are considered, for a new construction and an existing building: $\mathrm{Q}_{4 \mathrm{~Pa}}=0.6 \mathrm{~m}^{3} \cdot \mathrm{h}^{-1} \cdot \mathrm{m}^{-2}$ and $\mathrm{Q}_{4 \mathrm{~Pa}}=1.6 \mathrm{~m}^{3} \cdot \mathrm{h}^{-1} \cdot \mathrm{m}^{-2}$, respectively. Also, these air leakages are considered as evenly distributed on each façade of each floor.

(iii) Ventilation system: A sensitivity study was performed on three controlled mechanical ventilation systems: a mechanical ventilation system by extraction (VMC_EXT), a balanced mechanical ventilation system (VMC_DF_EQ) and a supply mechanical ventilation system (VMC_DF_SURP). The first two systems are commonly used in new buildings, and the third can be used as a protective solution because it minimises building depression and thus the entry of soil gas pollutants by convection. In this study, the sizing of these three ventilation systems is based on the French housing regulations, namely, the decree of 24 March 1982, amended on 15 November 1983. and using the French Standard NF DTU 68.3 [32]. For VMC_EXT, the system dimensioning is as followed. Self-adjustable air inlets are located in the bedrooms and the living room with an air inlet of "module 15" in each bedroom and two air inlets of "module 30" in the living room. The value "Q" of the module means that the airflow incoming through the air inlet is linearly interpolated between $0 \mathrm{~m}^{3} \cdot \mathrm{h}^{-1}$ and $\mathrm{Q} \mathrm{m} \mathrm{m}^{3} \cdot \mathrm{h}^{-1}$ for a depression level on either side of the air inlet between $0 \mathrm{~Pa}$ and 20 $\mathrm{Pa}$. For a depression level above $20 \mathrm{~Pa}$, the self-adjustable air inlet maintains an airflow of $Q \mathrm{~m}^{3} \cdot \mathrm{h}^{-1}$. Mechanical exhaust airflows are imposed in technical rooms. Values are $45 \mathrm{~m}^{3} \cdot \mathrm{h}^{-1}, 15 \mathrm{~m}^{3} \cdot \mathrm{h}^{-1}, 30 \mathrm{~m}^{3} \cdot \mathrm{h}^{-1}$ and $30 \mathrm{~m}^{3} \cdot \mathrm{h}^{-1}$ for the kitchen, the toilets of the ground floor, the bathroom and the toilets of the first floor respectively. This leads to a basic air renewal of the dwelling of $120 \mathrm{~m}^{3} \cdot \mathrm{h}^{-1}$ which corresponds to $0.3 \mathrm{~h}^{-1}$. For VMC_DF_EQ, exhaust airflows dimensioning is the same than for VMC_EXT. Global mechanical insufflation is dimensioned to have the same value of $120 \mathrm{~m}^{3} \cdot \mathrm{h}^{-1}$ with the following repartition: $60 \mathrm{~m}^{3} \cdot \mathrm{h}^{-1}$ in the living room and $15 \mathrm{~m}^{3} \cdot \mathrm{h}^{-1}$ in each bedroom. For VMC_DF_SURP, the dimensioning is the same than for VMC_DF_EQ but with a coefficient of 0.9 affected on each mechanical exhaust airflow. Finally, for each ventilation system, the basic air renewal is then maintained approximately constant and of the same value of $0.3 \mathrm{~h}^{-1}$ in average. However, it could be slightly influenced along time by the variation of meteorological conditions and their impact on pressure levels of the dwelling, on stack effect and on wind effect on the envelope, affecting airflows through air leakages and thus the air renewal of the building.

\subsubsection{Evolution of the indoor concentration}

The calculations were conducted over a year for the different scenarios and considering the typical meteorological conditions of metropolitan France, enabling to collect the following parameters: outdoor air temperature, relative humidity, wind speed and direction. Fig. 11 shows, as examples of results for the case of floating slab (FS) with $\mathrm{Q}_{4 \mathrm{~Pa}}=0.6 \mathrm{~m}^{3} \cdot \mathrm{h}^{-1} \cdot \mathrm{m}^{-2}$ and the use of a mechanical ventilation system by extraction (VMC_EXT), the temporal evolution of different indoor parameters: the air renewal, the building depressurisation, the pollutant mass flux, and the indoor pollutant concentration. Nevertheless, the average annual, minimum and maximum concentrations are listed for each case in Table 4 to more easily analyse the 
variations in the results, particularly regarding the average or extreme exposure values.

\subsubsection{Analyses}

The performed calculations illustrate the interest of the development of this methodology to study the impact of vapor contaminants in the soil on future buildings that would be built on the site considered and according to the typological characteristics of these buildings. Different observations can be done based on this example of building sensitivity study. At first, the significant influence of the typology of the substructure is highlighted. The FS substructure, less airtight than the SS one, facilitates the entry of soil gas pollutants, implying higher indoor concentration of pollutants in average. Also, the level of air permeability of the building envelope can affect the indoor pollutant concentration. The more airtight the building is, the higher the indoor pollutant concentration is. This is a consequence of the slight decrease of the air renewal and the slight increase of the building depressurisation for the more airtight building. The impact of the ventilation system type can also be observed. The use of VMC_EXT induces a slight increase of the building depressurisation compared to the use of VMC_DF_EQ, inducing a higher pollutant mass flow rate entering the building and thus a higher indoor pollutant concentration. On the contrary, the use of VMC_DF_SURP tends to decrease the slight depressurisation of the building and thus enables to decrease the indoor pollutant concentration. Finally, for all cases, a significant temporal variation of indoor pollutant concentration is observed. This variation is mainly influenced by the variation of meteorological conditions, impacting the air renewal and the depressurisation levels of the building. All these trends are consistent with previous results studying the impact of ventilation systems on the indoor radon concentration [29].

At the end, a difference of one order of magnitude in terms of the indoor pollutant concentration can be observed depending on the studied configurations of the building. Thus, attenuation factor (ratio between indoor pollutant concentration and source pollutant concentration in the soil) values between $10^{-4}$ and $10^{-5}$ are observed with respect to the soil pollutant concentration given at $5 \mathrm{~m}$ depth. This result nevertheless shows the interest in the development of this method as well as the non-negligible influence of building characteristics on the indoor concentration of the pollutant.

\section{Discussion}

This section presents the framework of use, the limits and the potentialities of the novel methodology, accounting for the encountered pollution typologies, the experimental conditions, and the interpretation and use of the results.

\subsection{Typology of soil pollution in relation to the building}

Three situations of buildings can be distinguished regarding the location of soil pollution: (1) pollution under the future building; (2) pollution outside the influence of the future building, or even the site; and (3) pollution dissolved in the aquifer. For the first two categories, three pollution situations can be considered, i.e., pollution in the vadose zone with residual adsorbed pollution or organic phase and pollution by 
organic phase in the water table fluctuation zone. Table 5 summarises all the situations that can be encountered.

Considering the assumptions made to adapt the SEM model for the box, it appears that this methodology is more adapted to certain typologies of soil pollution than to others. Indeed, the SEM is based on a contaminant source located directly underneath the building, below the convective zone of the "experimental box", between 1 and $12 \mathrm{~m}$. Thus, this methodology is particularly relevant for the following situations, provided that the source is located directly underneath the building, between 1 and $12 \mathrm{~m}$ deep: pollution by organic phase in the vadose zone (1b) or at the water table (1c) and pollution dissolved in the aquifer (distant source with impact only dissolved at this distance) (3). The applicability of this methodology to other typologies and/or with a source located in the convective zone in soil generated by the building has to be considered with caution because it is outside the model development assumptions. Finally, it is important to emphasise that the more the soil pollution typology approaches a homogeneous source located underneath the box and outside its convective zone, the more the evaluation of the "equivalent homogeneous concentration" will be relevant. On the other hand, if the reality moves away from these cases (source in the convective zone of the box and/or heterogeneous source), the evaluation will lose its relevance.

\subsection{Location of the experimental box}

The choice of the zone for the tests with the chamber must be reflected and relevant according to the probable preliminary studies realised to characterise the pollution of the site as well as to the building development plan. It is relevant to realise tests on several areas where future buildings would be located. Finally, a bottom excavation test on the site where the building will be built can be judicious.

\subsection{Conduction of the tests}

It appears that this device remains relatively easily transportable, installable and dismountable in situ. Once the chamber is installed, it is advisable to start the experiments in a relatively short time (less than two weeks depending on weather conditions) to maintain the integrity of the experimental conditions, especially the airtightness of the anchor on the floor. Care should be taken to conduct the tests under stable hygro-meteorological conditions, with a wind of less than $2 \mathrm{~m} / \mathrm{s}$ and when outside temperatures are not too low. Finally, regarding the duration of the tests and considering the stabilisation times evaluated in the framework of this study, the tests must last longer than several hours or a day to obtain stabilised results. The influence of hygro-meteorological conditions on the concentration plumes and ultimately on the transfers measured with the developed device is significant. Thus, one of the constraints of this methodology is to carry out tests only under favourable hygro-meteorological conditions.

\subsection{Interpretation of the results}

The interpretation of the results of this methodology permits us to determine: 
- An equivalent air permeability of the soil located in the convective zone of the ground under the box.

- A pair of values (equivalent homogeneous concentration, depth) that are representative of the emission of pollution (which may be heterogeneous) of the contaminated site. Each of these pairs of values is a solution of the problem. However, it is necessary to be able to set the depth of this source in a relevant way compared to the real situation that must be modelled and then to be able to use it for the study of the entire transfer of the pollutant from the soil to the building.

If the results obtained are satisfactory, it should be noted that the knowledge of the input parameters for the building (depression, air renewal rate and stable bearing of the concentration inside the box), the properties of the soil below the box (permeability to the air and diffusion coefficient) and a preliminary knowledge of the pollution and lithologies in the soil is decisive for the accuracy of the results. These parameters are also necessary for any use of a soil pollutant transfer model [33].

Finally, it appears that this methodology is more suited to a typology of soil pollution from a homogeneous source located underneath the box and beyond its convective zone.

\subsection{Exploitation of the results}

Once the experimental results are interpreted in terms of an equivalent homogeneous concentration associated with a given depth, these data can be used in transfer models [27] for evaluating indoor building concentrations. Finally, one of the interests of the methodology is to couple these soil/building transfer analytical models with a ventilation model to evaluate the indoor concentration of soil gaseous pollutants in realistic configurations considering the relevant parameters of the building. This approach provides complementary knowledge of the relative impact of building choices in a land development project: building typology (type of substructure and geometric elements), ventilation systems and regimes.

\section{Conclusion}

This study presented a novel methodology to complement the tools and methods for characterising soils contaminated by vapors and for assessing their impact on the indoor environments of future buildings that would be built on these sites.

Regarding the general methodology of "equivalent homogeneous concentration" evaluation, the relevance of the method and certain limits or questions could be underlined. It can be noted that the more the reality of the typology of soil pollution approaches a rather homogeneous source located underneath the box and outside its convective zone, the more the evaluation of the "equivalent homogeneous concentration" will be relevant. If the reality moves away from these cases (source in the convective zone of the box and/or heterogeneous source), the evaluation risks losing its relevance. 
Once this equivalent homogeneous concentration has been defined for a specific site, it has been integrated into our soil/building transfer models associated with a building ventilation model for the prediction of the indoor concentration of the contaminant. The analysis of the concentrations over a year permits us to evaluate the risks of exposure in realistic configurations. Calculations undertaken as illustrative examples highlight the significant impact of some building characteristics on the resultant indoor pollutant concentration.

Thus, this methodology has been applied to an in situ configuration and compared to existing methods for soil characterisation. It appears to hold promise as a complementary tool for ground characterisation and to constitute complementary support for decision-making methods. Its main interests are to be a nonintrusive methodology. It could be used to conduct exhaustive ground pre-characterisation and indoor air assessments for future buildings.

Acknowledgements: This study has been performed in the framework of the CAPQAI project co-financed by ADEME (APR Gesipol 2014): CSTB, LaSIE, Ineris, BURGEAP, and Grand-Lyon.

\section{References:}

[1] Burk T., Zarus G., 2013. Community Exposures to Chemicals through Vapor Intrusion: A Review of Past ATSDR Public Health Evaluations, J Environ Health. 75(9): 36-41.

[2] US-Health Department, 2007. Agency for Toxic Substances and Disease Registry. Evaluating Vapor Intrusion Pathways at Hazardous Waste Sites Introduction Volatile organic chemicals. Department of Health and Human Services toxicological.

[3] Shen R. Suuberg E.M., 2014. Analytical quantification of the subslab volatile organic vapor concentration from a non-uniform source. Environmental Modelling \& Software Journal 54 (2014) 1-8. http://dx.doi.org/10.1016/j.envsoft.2013.12.007

[4] Traverse S., Schäfer G., Chastanet J., Hulot C., Perronnet K., Collignan B., Cotel S., Marcoux M., Côme J.M., Correa J., Quintard M., Pepin L., 2013. Evaluation des transferts de COV du sol vers l'air intérieur et extérieur. Guide méthodologique. Projet FLUXOBAT. 257 pp. In French

[5] Kienbusch, M.R., 1986. Measurement of Gaseous Emission Rates from Land Surfaces Using An Emission Isolation Flux Chamber, Users Guide, EPA/600/886/008, NTIS \#PB86-223161.

[6] Bart E., Schmidt C., 1990. Estimation of Baseline Air Emissions at Superfund Sites, Air/Superfund National Technical Guidance Study Series, Vol II, EPA-450/189- 002a.

[7] Pokryszka Z., Tauziède C., 1999; Method of measuring surface emissions of methane, International Conference on Latest Achievements in the Field of Mine Ventilation, Fire and Methane Hazard Fighting, 22-24 April 1999, Szczyrk, Poland 
[8] Malherbe L., Hulot C., Pokryszka Z., Rouïl L., 2003. Caractérisation des flux de gaz émis par un sol pollué, DÉCHETS - REVUE FRANCOPHONE D'ÉCOLOGIE INDUSTRIELLE - Nº 32. In French

[9] Cotel S., Schäfer G., Traverse S., Marzougui-Jaafar S., Gay G., Razakarisoa O., 2015. Evaluation of VOC fluxes at the soil-air interface using different flux chambers and a quasi-analytical approach. Water Air Soil Pollut 226: 356. https://doi.org/10.1007/s11270-015-2596

[10] Maier M., Mayer S., Laemmel T., 2019. Rain and wind affect chamber measurements, Agricultural and Forest Meteorology, Volume 279, 15 December (2019), 107754

[11] Verginelli, I., Pecoraro, R., Baciocchi, R., 2018. Using dynamic flux chambers to estimate the natural attenuation rates in the subsurface at petroleum contaminated sites. Sci. Total Environ. (2018), 619, 470-479.

[12] Sihota N.J., MayerK.U., 2015. Comparison of Source Zone Natural Attenuation Rates At Crude Oil and Ethanol-Blended Fuel Release Sites, Bioremediation Journal (2015), 19:3, 218-230.

[13] Gallego, E., Perales, J.F., Roca, F.J., Guardino, X., 2014. Surface emission determination of volatile organic compounds (VOC) from a closed industrial waste landfill using a self-designed static flux chamber. Sci. Total Environ. 470, 587-599.

[14] Cal/EPA, 2011. Department of toxic substances control California environmental protection agency. Final guidance for the evaluation and mitigation of subsurface vapor intrusion to indoor air/ Vapor Intrusion - Conceptual Model, vapor intrusion guidance.

[15] Diallo T.M.O, Collignan B., Allard F., 2013. Analytical quantification of airflows from soil through building substructures. Building Simulation. 6: 81. https://doi.org/10.1007/s12273-012-0095-2

[16] Bjorklund B.S., Schmidt C.E., Lee H.L., Streeter R.A., 2002. Air Pathway Analysis Characterizing Potential Exposure from a Dissolved-Phase Groundwater Plume Using Direct Flux Measurement. In the Proceedings of the Air and Waste Management Association Symposium on Air Quality Measurement Methods and Technology, San Francisco, California; November 13 - 15, 2002.

[17] Schmidt C.E., Babyak A., Menatti J., 2004. Comparison of Static Chamber and Dynamic Chamber Technology for Assessing Infiltration of Soil Gas into Structures. In the Proceedings of the Air and Waste Management Association Annual Meeting, Indianapolis, Indiana; June 22 - 25, 2004.

[18] Copeland T.L., Van de Water J.G., 2004. Reducing Uncertainties in Health Risk Characterization: Methodologies for Assessing Indoor Air Exposure to Carcinogens. In the Proceedings of the Air and Waste Management Association Annual Meeting, Indianapolis, Indiana; June 22 - 25, 2004. 
[19] Sager S.L., Braddy L.D., Day C.H., 1997. The Infiltration Ratio in Vapor Intrusion Calculations. In the Proceedings of the Society for Risk Analysis Annual Meeting, Washington D.C.; December 9, 1997.

[20] Heggie A.C., Stavropoulos B., 2010. Evaluating Vapor Intrusion Risk Using Comparative Dynamic and Passive Flux Chambers at a TCE Impacted Site in Sydney, Australia. AWMA (Air \& Waste Management Association), Vapor Intrusion 2010 - September 29-30, 2010 • Chicago, IL 2010.

[21] Heggie A.C., Stavropoulos B., 2018. Passive diffusive flux chambers - a new method to quantify vapor intrusion into indoor air, Environ. Sci.: Processes Impacts, 20, 523-530. http://dx.doi.org/10.1039/C7EM00569E.

[22] US-EPA, 2002. Draft Guidance for Evaluating the Vapor Intrusion to Indoor Air Pathway from Groundwater and Soils (Subsurface Vapor Intrusion Guidance). United States Environmental Protection Agency. Office of Solid Waste and Emergency Response. November 2002.

[23] DGPR, 2017. "Méthodologie nationale de gestion des sites et sols pollués » Ministère de la Transition Ecologique et Solidaire. In French

[24] Collignan B, Powaga E., 2014. Procedure for the characterization of radon potential in existing dwellings and to assess the annual average indoor radon concentration. Journal of Environmental Radioactivity; 137:64-70. doi: 10.1016/j.jenvrad.2014.06.024

[25] Marzougui Jaafar S., 2013. Transfert de composés organo-chlorés depuis une zone source localisée en zone non saturée d'un aquifère poreux vers l'interface solair: expérimentations et modélisations associées. Thèse de doctorat, Université de Strasbourg, janvier 2013. In French

[26] Liu C., Ball W.P., 1999. Application of inverse methods to contaminant source identification from aquitard diffusion profiles at Dover AFB, Delaware. Water Resources Research, vol. 35, no. 7, pp 1975-1985.

[27] Diallo T.M.O, Collignan B., Allard F., 2015. 2D Semi-empirical models for predicting the entry of soil gas pollutants into buildings. Building and Environment 85 (2015) 1e16. http://dx.doi.org/10.1016/j.buildenv.2014.11.013

[28] Demouge F., 2018. Mathis: user's guide. [Research Report] CSTB - Centre scientifique et technique du bâtiment. 2018. ( https://hal.archives-ouvertes.fr/hal01529617/>

[29] Collignan B, Powaga E., 2017. Impact of ventilation systems and energy savings in a building on the mechanisms governing the indoor radon activity concentration. Journal of Environmental Radioactivity https://doi.org/10.1016/j.jenvrad.2017.11.023

[30] Chastanet J., Traverse S., Côme JM. (2018). Variabilité des concentrations dans les gaz du sol et des transferts vers l'air intérieur des polluants volatils. Modélisations numériques de différentes configurations de sol, de pollution et de perméabilité de 
dalle de bâtiment. Projet EFEMAIR. Collection expertise ADEME. Mai 2018. 33pp In French

[31] NF EN ISO 9972. Thermal performance of buildings - Determination of air permeability of buildings - Fan pressurization method. October 2015.

[32] NF DTU 68.3, 2013. Building works - Mechanical ventilation installations:

General rules for calculation, design and execution, June 2013

[33] Provoost J, Bosman A., Reijnders L, Swartjes F, Bronders J, Touchant K., Swartjes F., 2010. Vapor intrusion from the vadose zone-seven algorithms compared. J Soils Sediments. 10:473-483 DOI 10.1007/s11368-009-0127-4 


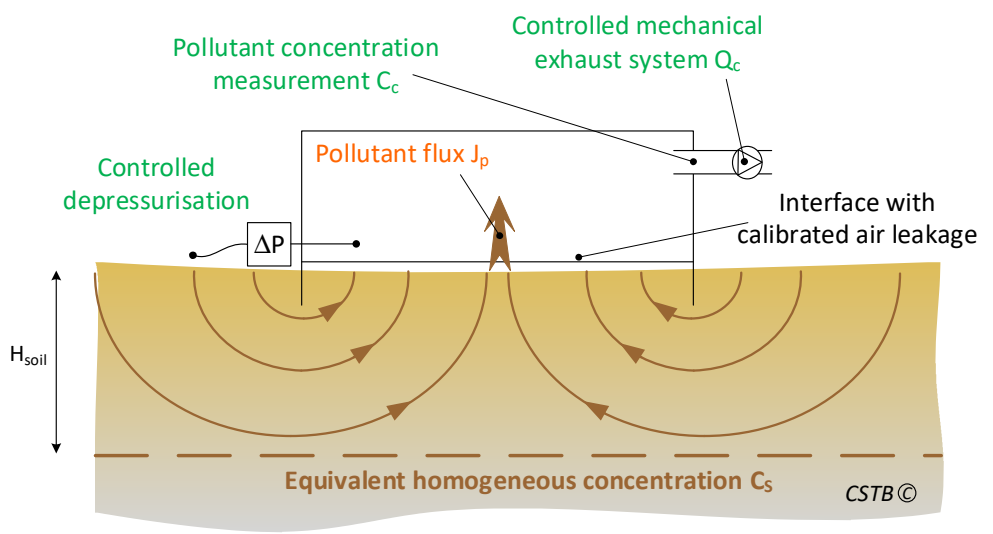

Fig. 1. Principle of the novel "experimental box".

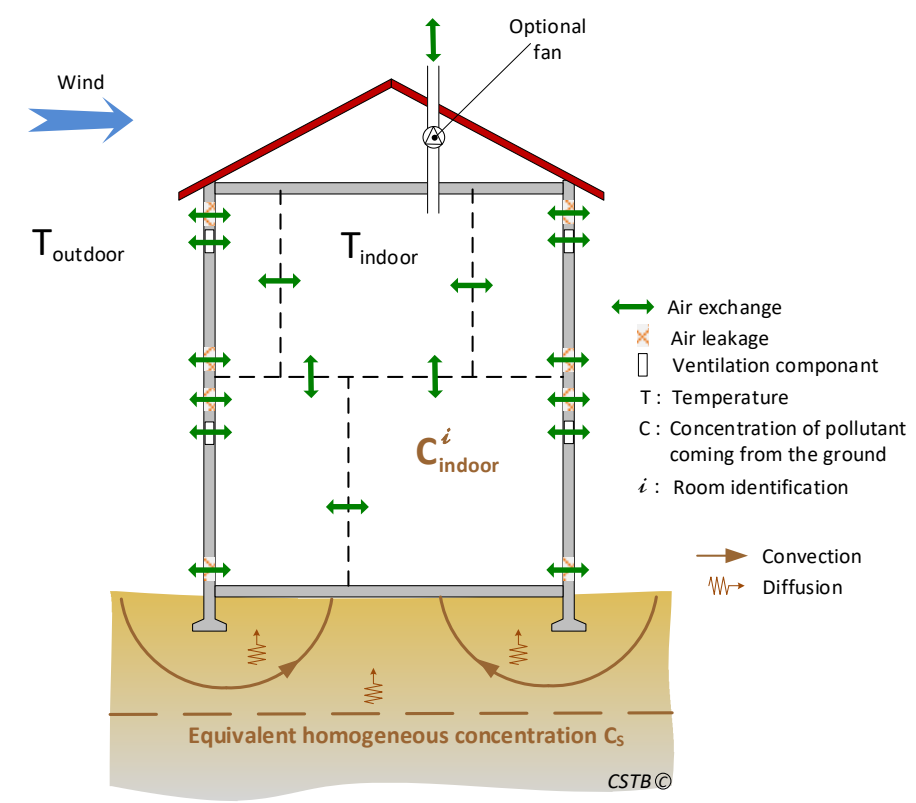

Fig. 2. Scheme of the integration of SEM in the ventilation model. 


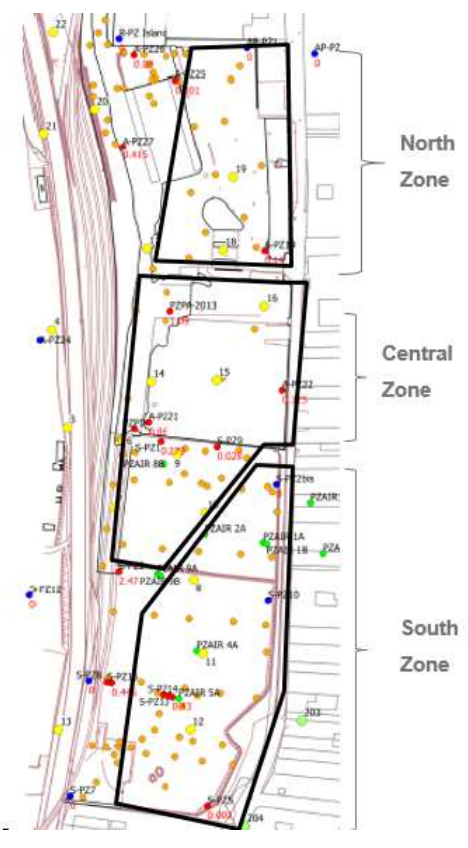

Fig.3. Map of the different zones of the experimental site.

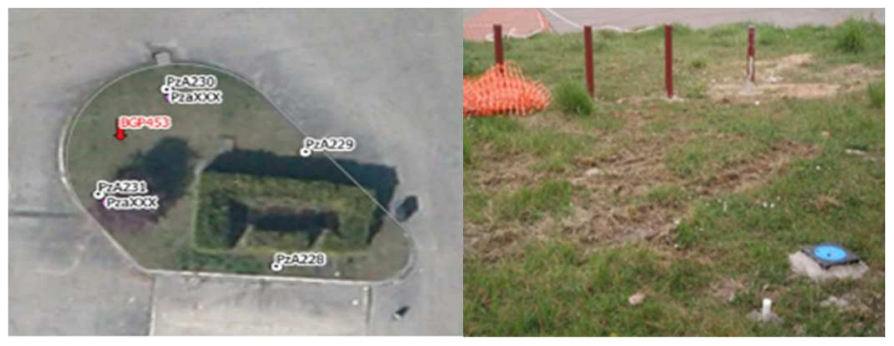

Fig. 4. Views of the instrumented area.

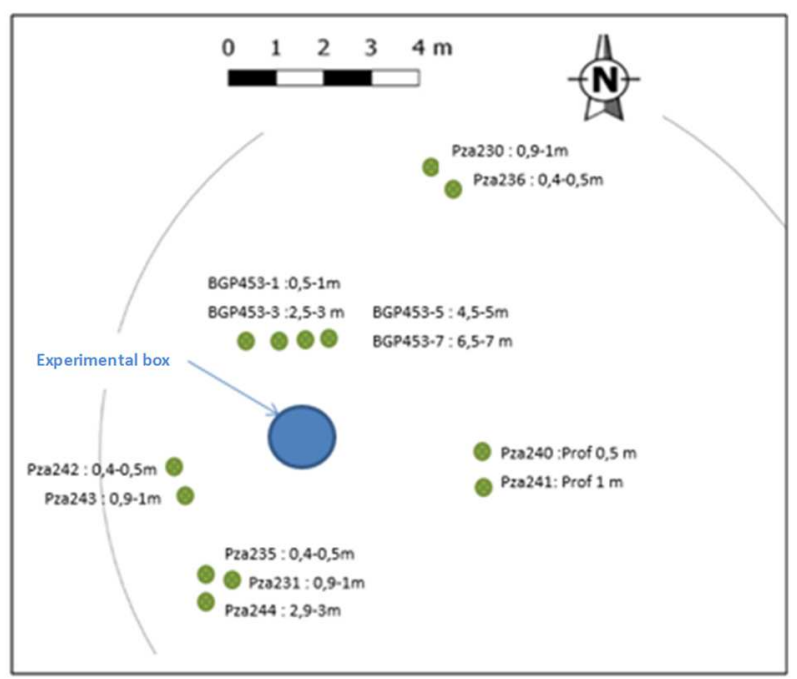

Fig. 5. Scheme of the instrumented area. 


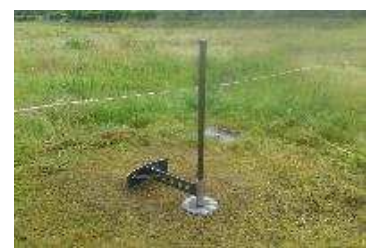

Preparation of a trench for the ground anchoring of the box

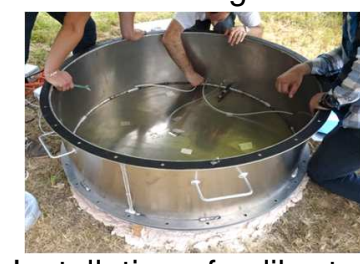

Installation of calibrated permeability interface and subwoofer

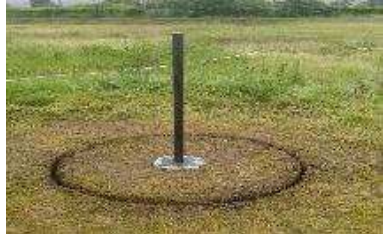

Trench realized

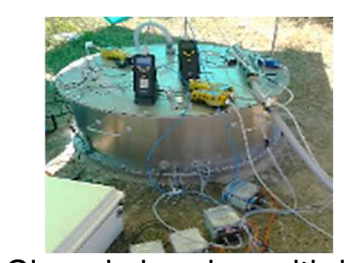

Closed chamber with its instrumentation

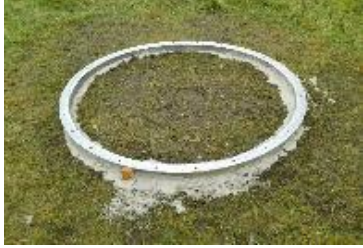

Installation of a skirt for anchoring the chamber

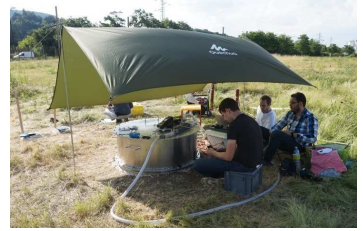

Test in process

Fig. 6. Presentation of the steps of onsite installation of the chamber.
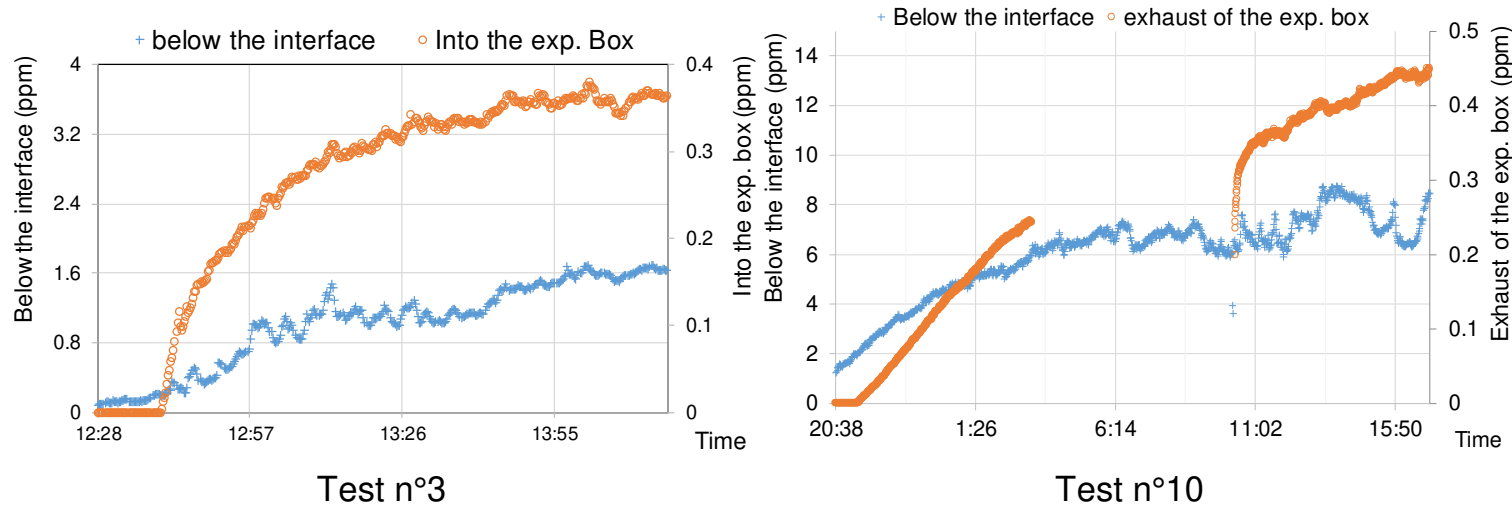

Fig. 7. Presentation of the concentration evolutions during tests $n^{\circ} 3$ and $n^{\circ} 10$. 


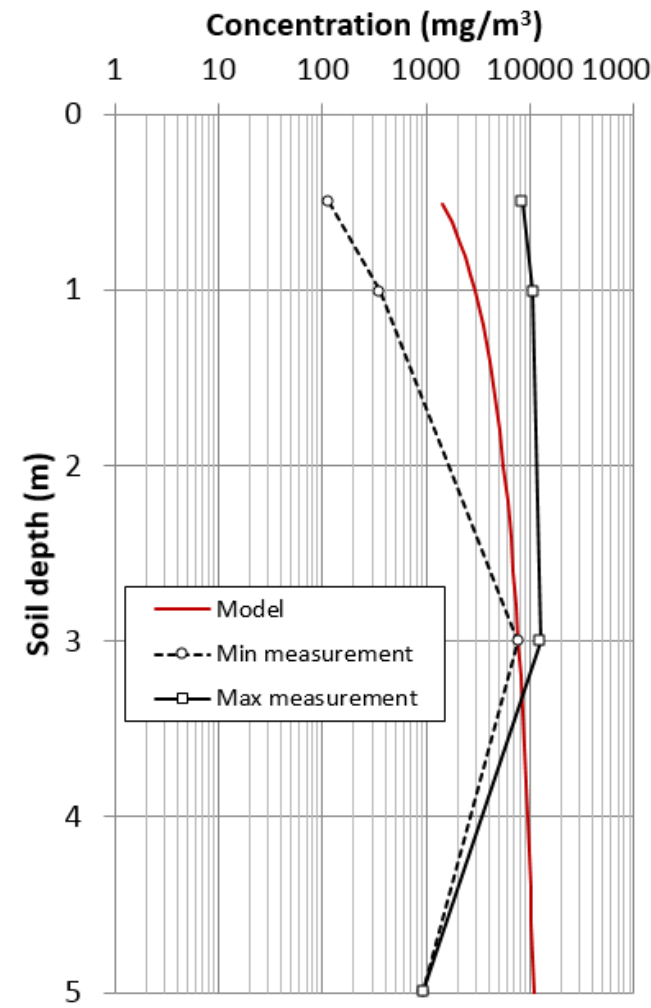

Test $\mathrm{n}^{\circ} 3$

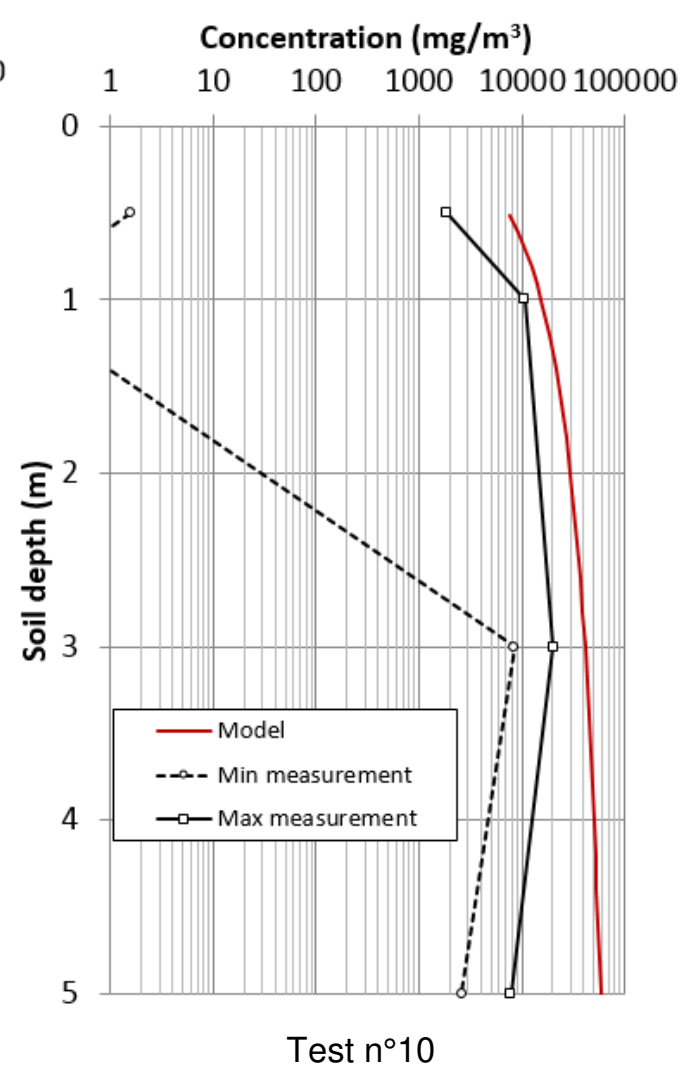

Fig. 8. Ground concentration profiles measured and modelled below the box
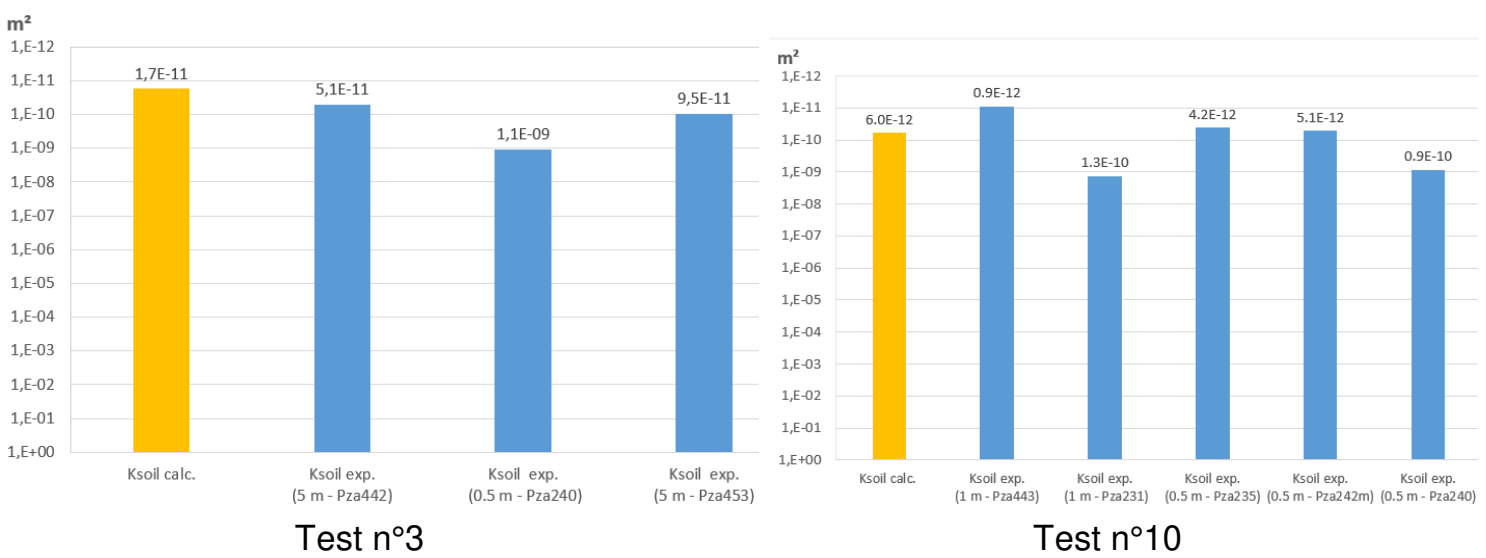

Fig. 9. Comparison between calculated (orange) and measured (blue) soil air permeability for tests $n^{\circ} 3$ and $n^{\circ} 10$. 


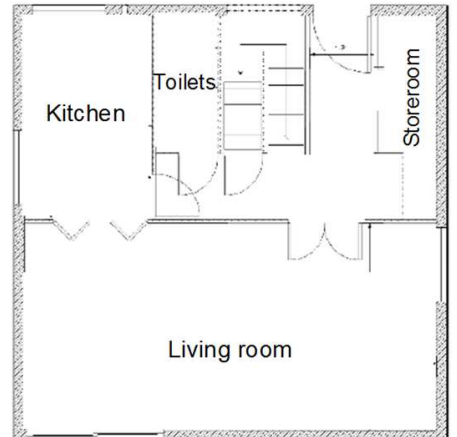

Level 1

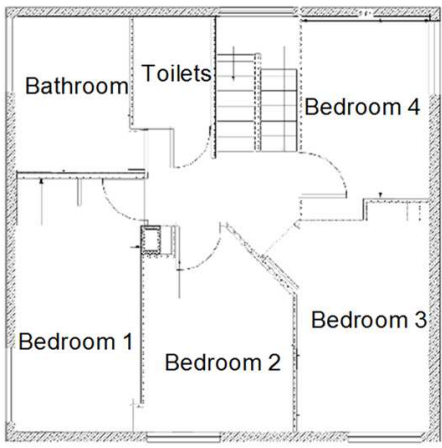

Level 2

Fig. 10. Description of the reference house.

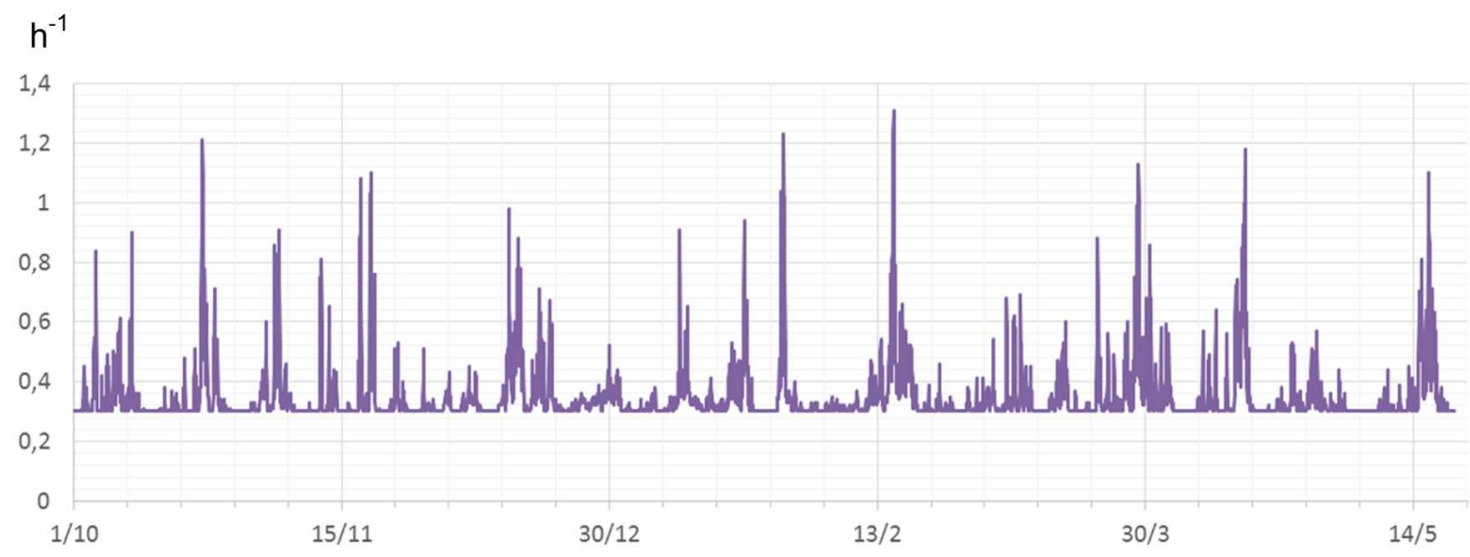

Air renewal in the building

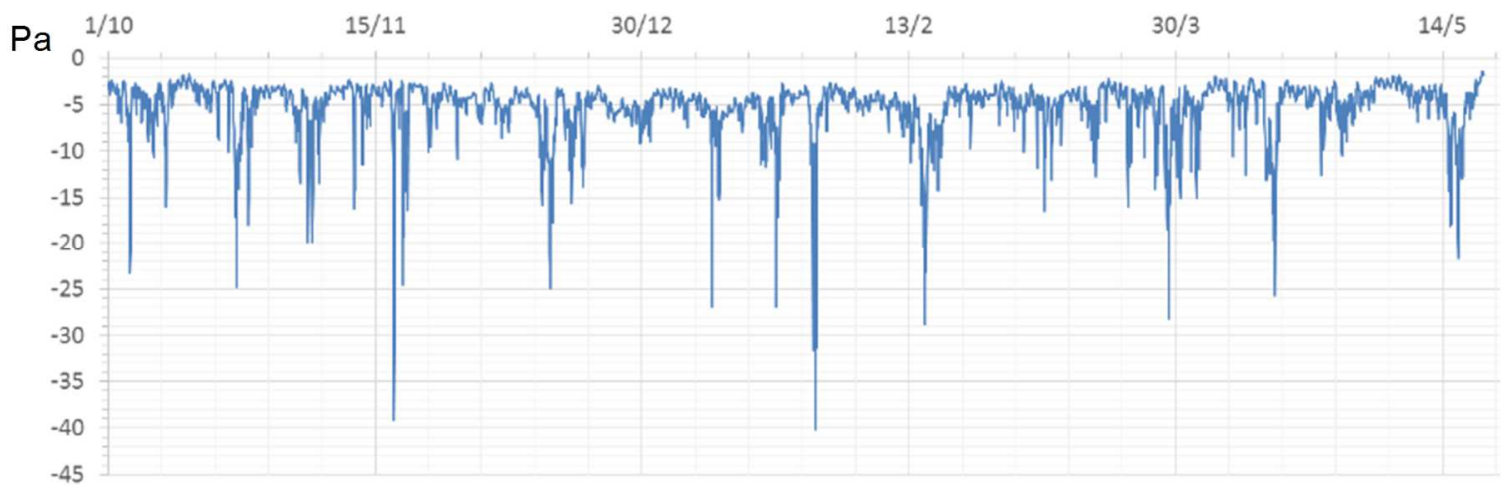

Building relative pressure 


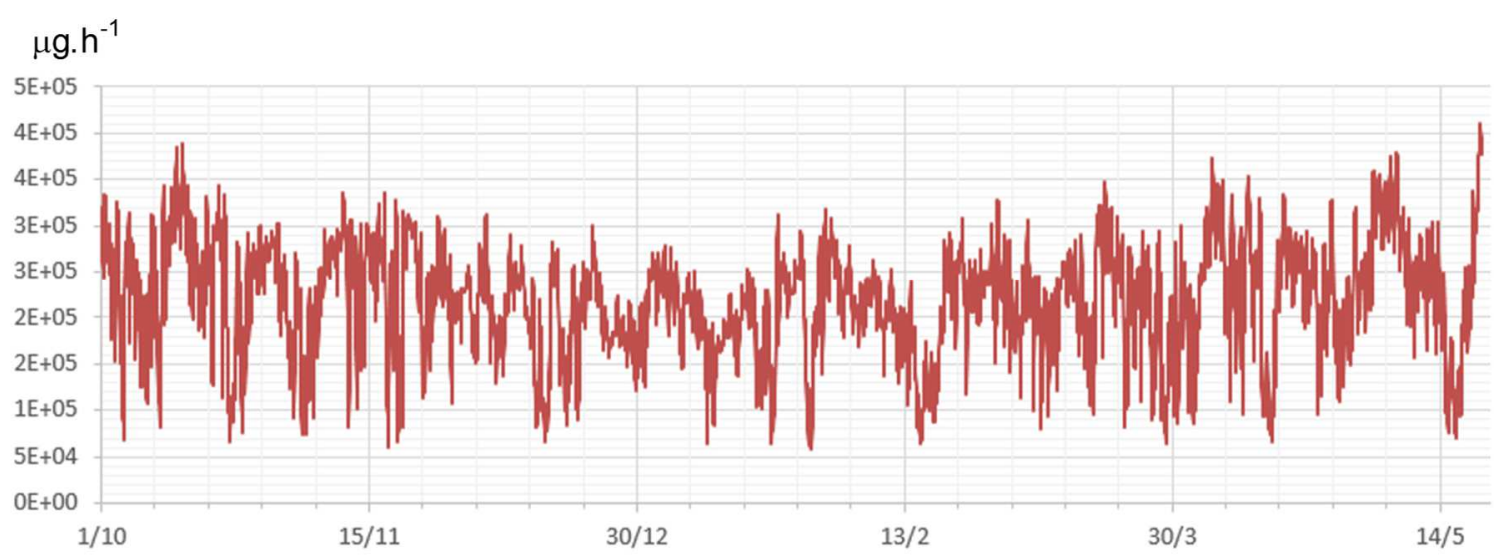

Mass flow rate of the pollutant entering the building

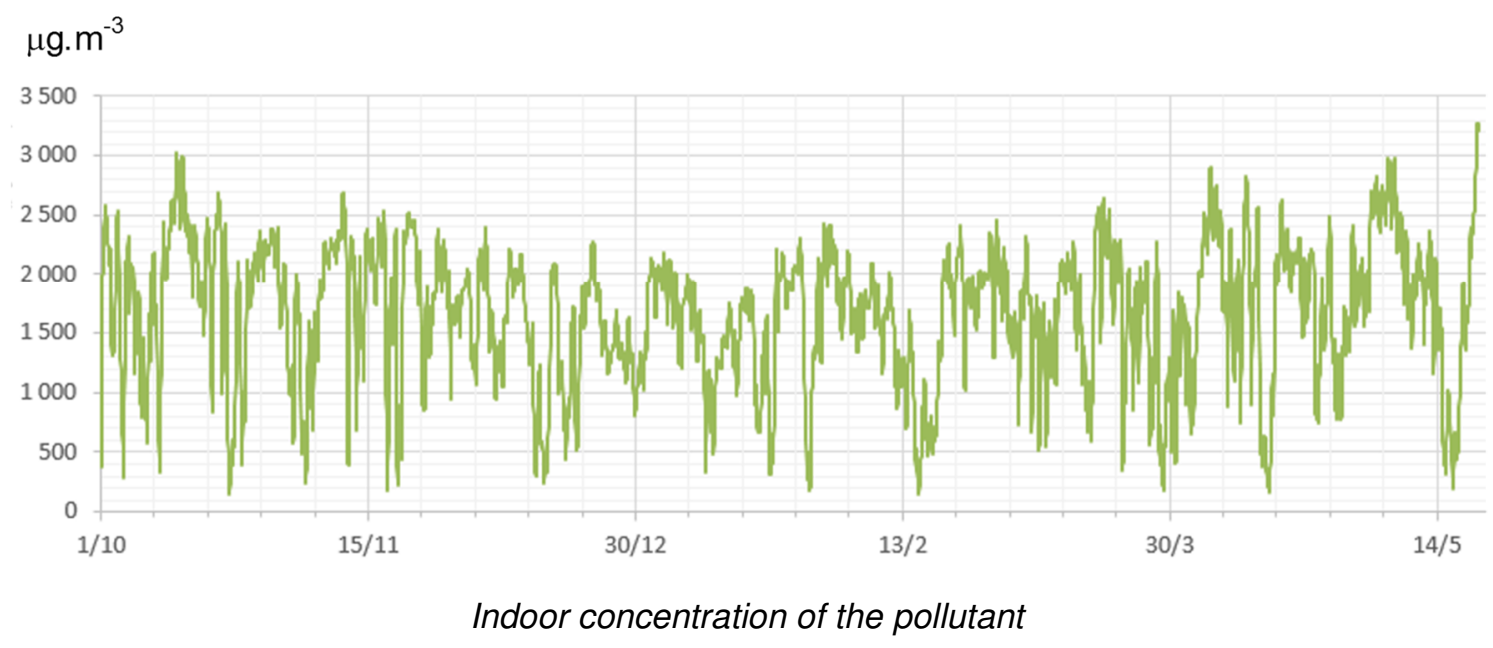

Fig. 11. Examples of temporal evolution of the building air renewal, relative pressure, pollutant flow rate and indoor concentration.

Case of floating slab (FS) with $\mathrm{Q}_{4 \mathrm{~Pa}}=0.6 \mathrm{~m}^{3} \cdot \mathrm{h}^{-1} \cdot \mathrm{m}^{-2}$ and the use of a mechanical ventilation system by extraction (VMC_EXT). 


\begin{tabular}{ccccc}
\hline Test & $\begin{array}{c}\text { Steady state } \\
\text { Concentration at } \\
\text { the exhaust of } \\
\text { the box }\left(\mathrm{mg} / \mathrm{m}^{3}\right)\end{array}$ & $\begin{array}{c}\text { Steady state } \\
\text { Concentration } \\
\text { inside the box } \\
\left(\mathrm{mg} / \mathrm{m}^{3}\right)\end{array}$ & $\begin{array}{c}\text { Mean box } \\
\text { depressurisation } \\
\text { relative to outside } \\
(\mathrm{Pa})\end{array}$ & $\begin{array}{c}\text { Mean } \\
\text { extracted } \\
\text { flow in the } \\
\text { box }\left(\mathrm{m}^{3} / \mathrm{h}\right)\end{array}$ \\
\hline 3 & $0.46^{*}$ & Not measured & 10.6 & 1.57 \\
10 & $1.73^{* *}$ & 3.2 & 21.0 & 0.55
\end{tabular}

* This value corresponds to the limit of quantification for the mass of aliphatic hydrocarbons using the activated carbon sampling. It was used for the following developments and the assessment of "equivalent homogeneous concentrations" in $\S 3.4$

** This value corresponds to an evaluation from the concentration inside the box multiplied by 0.54 ; coefficient calculated from the results of another test.

Table 1. Experimental steady state conditions for tests $n^{\circ} 3$ and $n^{\circ} 10$.

\begin{tabular}{lc}
\hline \multicolumn{1}{c}{ Characteristics of the building } \\
\hline Area of the floor $\left(\mathrm{m}^{2}\right)$ & 81 \\
Height of the building $(\mathrm{m})$ & 5 \\
Volume of the building $\left(\mathrm{m}^{3}\right)$ & 405 \\
Length of façades North, East, South et West $(\mathrm{m})$ & 9 \\
Surface of building envelope expect the floor $\left(\mathrm{m}^{2}\right)$ & 261 \\
Thickness of the slab $(\mathrm{m})$ & 0.2 \\
The permeability of the slab $\left(\mathrm{m}^{2}\right)$ & $1 \mathrm{E}-13$ \\
Diffusion Coefficient of the slab $\left(\mathrm{m}^{2} \cdot \mathrm{s}^{-1}\right)$ & $1 \mathrm{E}-08$ \\
Thickness of the gravel layer $(\mathrm{m})$ & 0.5 \\
Permeability of the gravel layer $\left(\mathrm{m}^{2}\right)$ & $1 \mathrm{E}-09$ \\
Thickness of the foundation wall $(\mathrm{m})$ & 0.3 \\
Depth of the foundation wall $(\mathrm{m})$ & 0.5 \\
\hline \multicolumn{1}{c}{ Indoor conditions } \\
\hline Indoor temperature $\left({ }^{\circ} \mathrm{C}\right)$ & $19^{\circ} \mathrm{C}$ \\
\hline
\end{tabular}

Table 2. Parameters for the reference case.

\begin{tabular}{cc}
\hline Characteristics of the modelled soil \\
\hline Permeability of the soil $\left(\mathrm{m}^{2}\right)$ & $6 \mathrm{E}-10$ \\
Diffusion coefficient of the soil $\left(\mathrm{m}^{2} \cdot \mathrm{s}^{-1}\right)$ & $4.4 \mathrm{E}-06$ \\
Depth of the « equivalent homogeneous concentration » $(\mathrm{m})$ & 5 \\
Value of « equivalent homogeneous concentration » $\left(\mu \mathrm{g} \cdot \mathrm{m}^{-3}\right)$ & $2.7 \mathrm{E}+07$ \\
\hline
\end{tabular}

Table 3. Characteristics of the soil simulated.

\begin{tabular}{cccccc}
\hline \multicolumn{2}{c}{ Configurations of the building } & \multicolumn{2}{c}{ Concentration of the pollutant $\left(\mu \mathrm{g} \cdot \mathrm{m}^{-3}\right)$} \\
\hline $\begin{array}{c}\text { Typology of the } \\
\text { substructure }\end{array}$ & $\mathrm{Q}_{4 \mathrm{~Pa}}\left(\mathrm{~m}^{3} \cdot \mathrm{h}^{-1} \cdot \mathrm{m}^{-2}\right)$ & $\begin{array}{c}\text { Ventilation } \\
\text { System }\end{array}$ & $\begin{array}{c}\text { Annual } \\
\text { Average }\end{array}$ & Minimum & Maximum \\
\hline FS & 0.6 & VMC_EXT & 664 & 77 & 1010 \\
SS & 1.6 & & 1980 & 82 & 3540 \\
FS & & & & 2468 & 3633
\end{tabular}




\begin{tabular}{|c|c|c|c|c|c|}
\hline SS & & & 383 & 69 & 467 \\
\hline FS & \multirow{2}{*}{0.6} & \multirow{4}{*}{$\underset{E Q}{V_{E} \mathrm{VMC}_{-}}$} & 2433 & 205 & 3265 \\
\hline SS & & & 436 & 66 & 672 \\
\hline FS & \multirow{2}{*}{1.6} & & 1774 & 89 & 2609 \\
\hline SS & & & 292 & 65 & 405 \\
\hline FS & \multirow{2}{*}{0.6} & \multirow{4}{*}{$\begin{array}{l}\text { VMC_DF- } \\
\text { SURP }\end{array}$} & 2155 & 235 & 2633 \\
\hline SS & & & 335 & 64 & 574 \\
\hline FS & \multirow{2}{*}{1.6} & & 1615 & 88 & 2240 \\
\hline SS & & & 254 & 63 & 351 \\
\hline
\end{tabular}

Table 4. Mean annual, minimum and maximum concentrations of the different building configurations modelled.

\section{1 - Pollution under the future building}

1.a - Residual pollution absorbed in the vadose zone

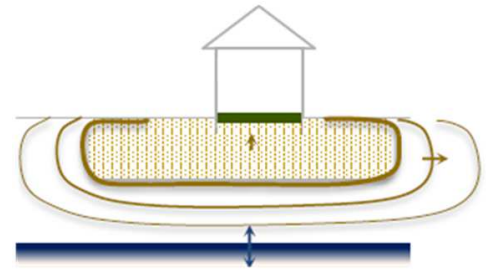

\section{2 - Lateral Pollution}

2.a - Residual pollution absorbed in the vadose zone

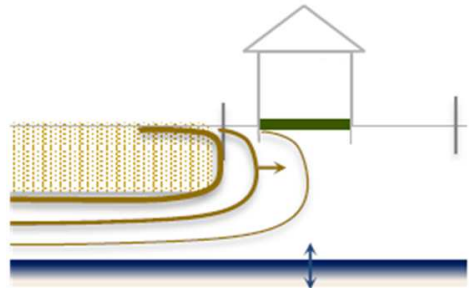

1.b - Pollution by organic phase in the vadose zone

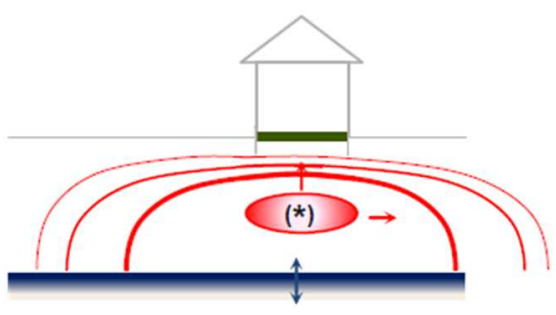

1.c - Pollution by organic phase in the water table fluctuation zone

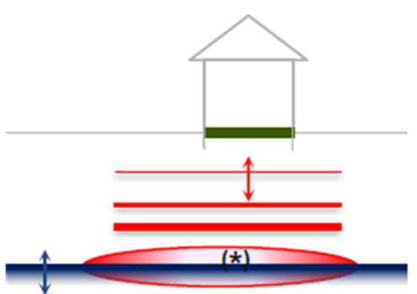

2.b - Pollution by organic phase in the vadose zone

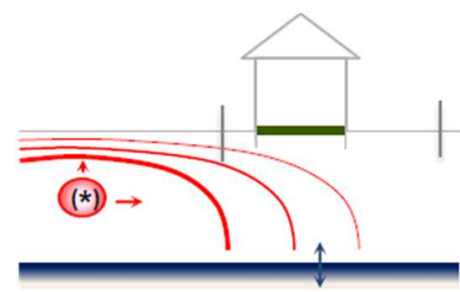

2.c - Pollution by organic phase in the water table fluctuation zone

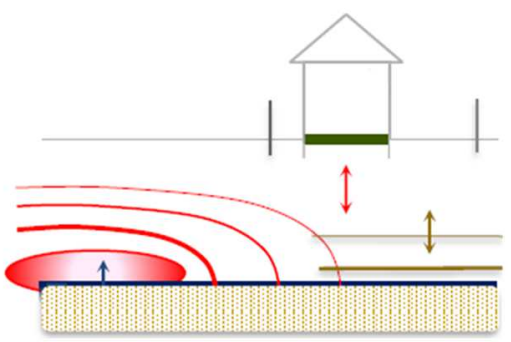

3 - Pollution dissolved in the aquifer (distant source with impact only dissolved at this distance) 


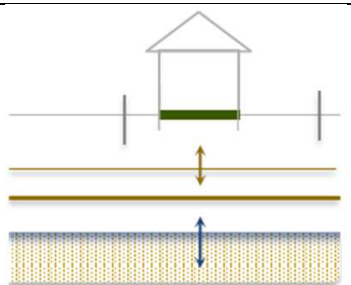

$\left({ }^{\star}\right)$ : The treatment of the pollution source in the form of an organic phase should be considered. It must be the subject of the technical and economic studies described in DGPR, 2017.

Table 5. Pollution situations encountered 


\section{Graphical Abstract}
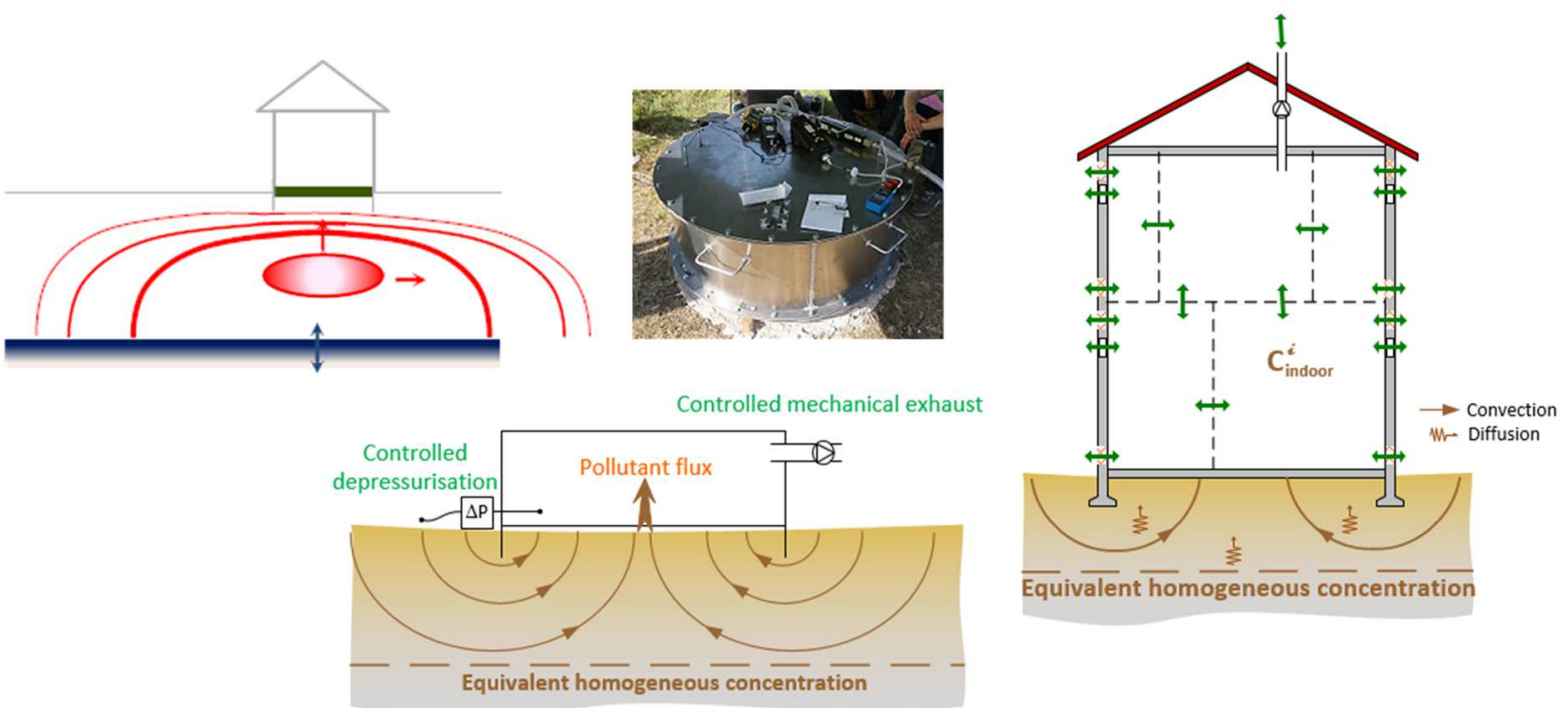